\title{
El IX Congreso Español de Sociología reúne en Barcelona a las personalidades más destacadas de este campo
}

Los organizadores se muestran satisfechos por los resultados conseguidos y califican el evento positivamente, al tiempo que confirman que la asistencia de cerca de mil trescientos congresistas afianza el creciente interés por la sociología en España

Del 13 al 15 de septiembre, se han dado cita en la ciudad condal 1.257 congresistas con motivo del IX Congreso Español de Sociología. Entre los asistentes se ha contado con la presencia de figuras de renombre del mundo de la sociología, como Salvador Giner, Emilio Lamo de Espinosa, Néstor García Canclini, Joaquín Arango o Fernando Vallespín, entre muchos otros. Bajo el lema «Poder, cultura y civilización», se ha debatido durante tres días sobre los cuatro temas esenciales de los simposios: sociedad laica; ciudadanía y pluralismo cultural; encuestas, comunicación y política; y la pobreza mundial.

Tal y como comentó el presidente saliente de la Federación Española de Sociología (FES) en el acto de clausura del evento, «el balance ha sido excelente y el número de asistentes confirma que existe un interés creciente por la sociología en España». En el Congreso se han presentado 1.127 documentos para los treinta grupos de trabajo de las diferentes disciplinas de la sociología.

En el acto de inauguración, celebrado el jueves 13 de septiembre, el conseller de Educación de la Generalitat de Catalunya, Ernest Maragall, y la secretaria de Universidades e Investigación, Blanca Palmada, hicieron un llamamiento a los sociólogos para que ejerzan una labor crítica, pero a la vez de equilibrio, con el poder y los medios. En este sentido, se habló del papel de las encuestas como herramienta de conocimiento y evaluación, pero también como elemento influenciador en la opinión pública. Fue precisamente el papel de las encuestas uno de los temas básicos del Congreso y el que centró el debate del tercer simposio, donde el presidente del Centro de Investigaciones Sociológicas (CIS), Fernando Vallespín, habló sobre la paradoja de que «por un lado se demuestre la necesidad de las encuestas para medir el pulso político y que, por otro lado, se perciba una crítica continua y sistemática hacia los resultados que muestran». Para Vallespín, «las encuestas acaban siendo un medio de instrumentalización de los intereses políticos y son usados para obje- 


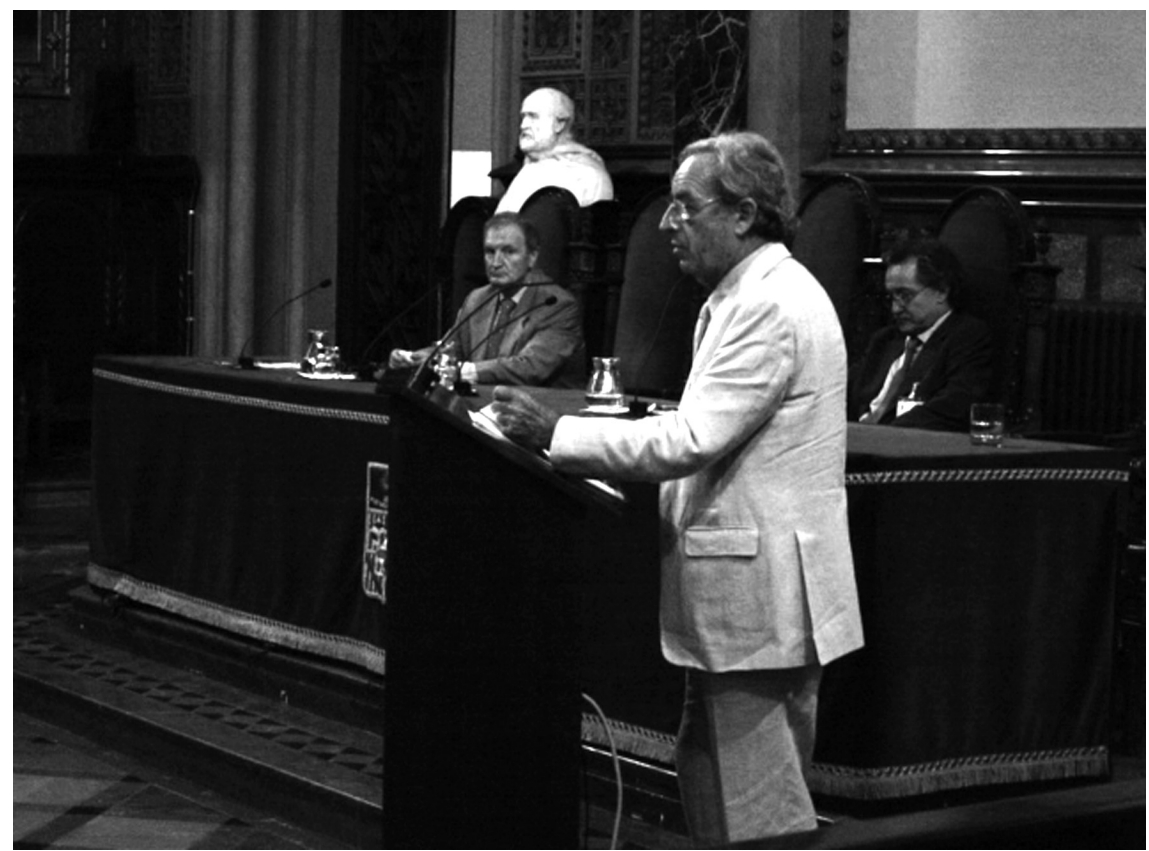

Intervención de Salvador Giner.

tivizar a la opinión pública». Respecto al uso que hacen de ellas los medios de comunicación, reclamó una mayor objetividad a la hora de interpretar los resultados.

Respecto a otras aportaciones también interesantes, cabe mencionar los diferentes puntos de vista de Emilio Lamo de Espinosa, catedrático de la Universidad Complutense de Madrid (UCM), y de Joan Estruch, director del Centro de Investigaciones en Sociología de la Religión de la Universidad Autónoma de Barcelona, acerca del «Presente y el futuro de la sociedad laica». Éste es el título del Simposio, en el que se discutió sobre identidad y religión, y donde Estruch defendió que existe una gran cantidad de grupos religiosos diferentes en un entorno de ciudadanía plural, por lo que las religiones dominantes deben acomodarse a esta nueva situación. Lamo de Espinosa, desde otra perspectiva, afirmó que se tiende a una concentración religiosa y de valores a escala mundial, pero en cambio a una heterogeneidad en el ámbito nacional.

Tanto en el simposio sobre «Ciudadanía universal y pluralismo cultural» como en el acto de clausura del Congreso, Néstor García Canclini, profesor investigador distinguido de la Universidad Autónoma Metropolitana de México, habló sobre las consecuencias, tanto directas como indirectas, que están produciendo los flujos migratorios en todo el planeta, y de cómo éstos influyen 


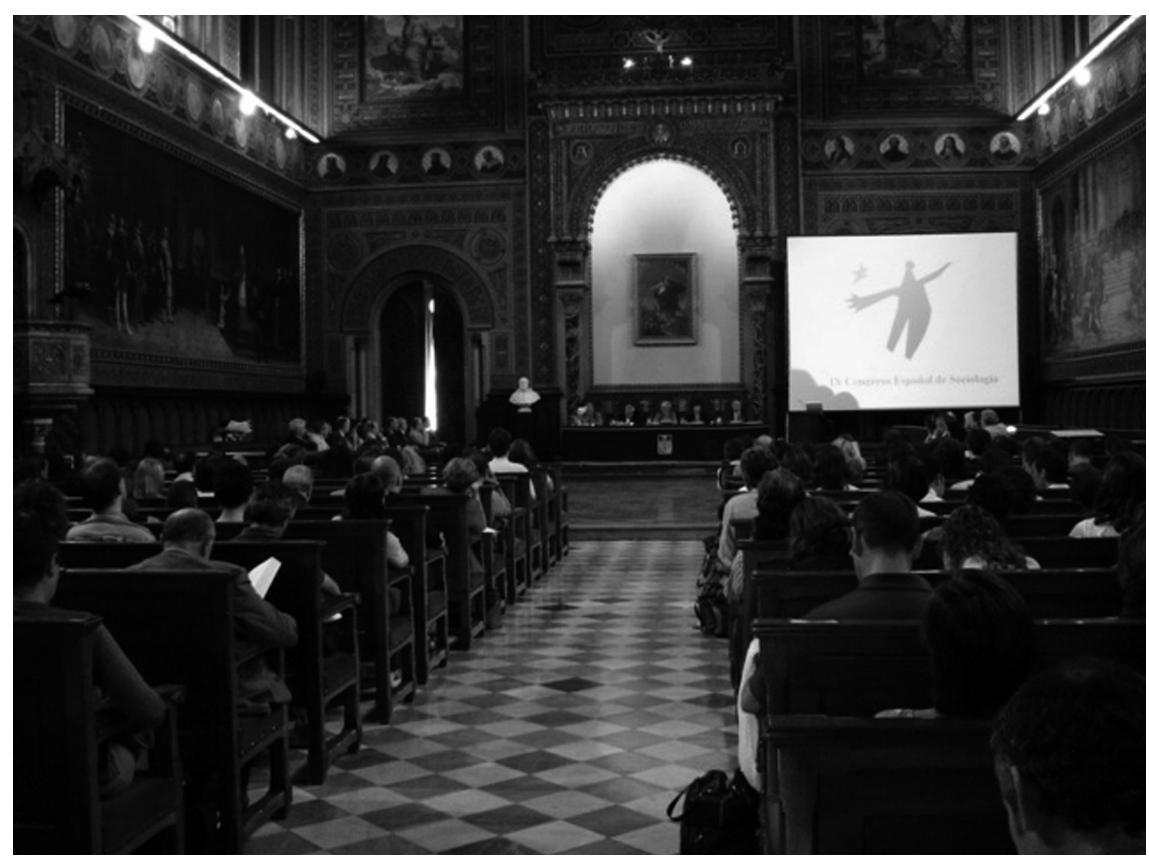

Visión de la sala de sesiones.

directamente en el terreno político, económico, político, social e incluso cultural de la ciudadanía.

En el simposio sobre «La pobreza en el mundo», coordinado por el director de la Fundación Sistema, José Félix Tezanos, la catedrática de sociología de la Universidad Autónoma de Barcelona, Carlota Solé, comentó el papel de la mujer en los países en vías de desarrollo. Milagros Hernández, directora general de Planificación y Evaluación de Políticas para el Desarrollo en el Ministerio de Asuntos Exteriores y de Cooperación, incidió en el compromiso de la política exterior española por la lucha contra la pobreza. El catedrático de sociología de la Universidad de Alicante, José María Tortosa, hizo alusión a las desigualdades que existen tanto dentro de los propios estados como entre el primer y el tercer mundo, y dibujó un panorama poco alentador para los próximos años al señalar que, a pesar de los esfuerzos realizados, «hoy en día nos encontramos con un nivel de desigualdad internacional superior al que existía en los años sesenta».

El IX Congreso Español de Sociología ha sido el primero que la FES ha realizado en Barcelona. Los dos próximos años también serán importantes para la sociología, ya que la ciudad catalana será sede del I Fórum Internacional de Sociología en el 2007 y del V Congrés Català de Sociologia en el 2008. 